\title{
BİR İHRACAT KARAR SÜRECI MODELİ DENEMESİ
}

\author{
Dr. F. Akın KOÇAK
}

\section{Giriş}

Günümüzdeki teknolojik gelişmeler sonucunda ülkeler arasındaki ekonomik sınırların ortadan kalkması, ulaşım ve bilgi akışının kolaylaşması ve artan rekabet, işletmeleri, yaşamlarını sürdürebilmek için, uluslararası piyasalarda da faaliyette bulunmaya zorlamaktadır. Bu nedenle de, işletmelerin uluslararasılaşmasına ilişkin çalışmalar son 10 yılda giderek yoğunlaşmışur. Bu yoğunlaşma büyük ölçüde küçük ve orta ôlçekli işletmelere yöncliktir. Zira küçük ve orta ölçekli işletmelerin, 1970 sonrası üstlendikleri; ülke ckonomilerinde büyüme, istihdam ve üretimi artırma rollerinde başarılı olmalanndan sonra, günümüzdcki bcklenen rolleri; bünyelerinde var olan ihracat potansiyelini uygulamaya geçirerek ihracatı artırmaları ve ülkelerin ödemeler dengesini iyileştirmcleridir ${ }^{1}$.

Uluslararasılaşma, işletmelerin ihracat, lisans anlaşmalan, franchasing, jointventure, stratejik işbirlikleri, doğrudan yatırım gibi uluslararası piyasalarda faaliyette bulunmaların kapsar. Thracat, bir pazar geliştirme stratejisi olarak uluslararasılaşmanın ilk aşamasıdır. Ihracatın uluslararası sürecin ilk aşama olarak kabul edilmesi; pazar ve politik riskleri minimize etmesi, sabit sermaye yatırımı gerektirmemesi ve düşük başlangıç maliyetlerine konu olmasından kaynaklanmaktadır ${ }^{2}$. Bu şekli ile de ihracat küçük ve orta ölçckli işletmelerin uluslararası piyasaya yönclmeleri ve deneyim kazanmalan açısından önemli bir altematiftir.

Türkiye'de bugünc kadar yapılan çalışmalar genellikle küçük ve orta ölçekli işletmelerin ihracat potansiyelini değerlendirmek için çeşitli teşvik uygulamalarının incelenmesi ile sınırlı kalmışur. Bu teşvikler ise genellikle; vergi muafiyeti ve iadeleri,

\footnotetext{
* A.U. Siyasal Bilgiler Fakültesi Araş̧ırma Görevlisi.

${ }^{1}$ A. Desmond O'Rouke, "Differences in Exporting Practices, Autitudes and Problems by Size of Firm", American Journal of Small Business, 1985, Vol: 9, No: 3, s:25.

${ }^{2}$ M. Mithat Uner, "Ankara Sanayi Odasına Kayıtlı Işletmeleri Ihracattan Alıkoyan Nedenler", Siyasal Bilgiler Fakültesi Dergisi, Prof. Dr. Yilmaz Günalía Armağan, Cilt: 49, Sayı:3-4, 1994, s:461.
} 


\section{F. AKIN KOÇAK}

F. AKIN KOÇAK

gümrük muafiyeti, enerji fiyatında indirim ve ihracat kredileri gibi finansal desteklerdir. Fakat küçük ve orta ölçekli işleı/melere damgasını vuran onun sahibi, girişimcidir ${ }^{3}$. Bu nedenle küçük ve orta olçekli işletmelere yơnelik çalışmalar yapılırken veya politikaląr geliştirilirken girişimci iizerindle, diğer bir deyişle insan faktörü üzerinde de durmak, davranışsal bir yaklaşım izlemelk gerekmektedir. Zira ay'n çevre şartlarından etkilenen, aynı sektördeki, hatta komşu işletmelerden biri ihracat yaparken diǧeri ihracat yapmámakıadır. Bu ise ancak itssan faktörü iie açıklanabilir. Bu nedenle, önemli olanın küçük ve orta olçekli işletme sahibinin ihracat karan almasımı etkileyecek faktörlerin belirlenmesidir.

Bu makalede kilçük ve: orta olçekli işletmelerin ihracat karar alma süreci incelenecektir. Makale iki amaç içermektedir; ilk olarak pazar geliştirme strateji olarak ihracát kararnn belirleyen faktörlerin, uluslararası pazarlama literatüründe ele alınışı da incelenerek, ortaya konması ve ikinci olarak da, belirlenen bu faktörlerin saha araşurması ile ihracat karanna etki dereceles inin belirlenmesidir.

\section{Konunun Literaliirde Ele Alınışı}

thracat davranışı literalïirde; uluslararası ticaretin arz yönünden ihracat davranışı yönüne, ihracat karar almal ve ihracat davranışınıa örgütsel belirleyicilerinin belirlenmesine kadar oldukça ğ!niş ve farklı perspektiflerde tartişılmaktadı ${ }^{4}$.

thracat karar süreci iss, işletme sahibinin özellikleri ile işletme ozzellikleri ve bunların arasındaki etkileşimi ve dış faktörlerden etkilenmeleri sonucunda oluşan karmaşıı bir süreçtir ${ }^{5}$. Bu şekli ile ihracat karar alma sürecinin literatürde ele alınışı, işlecme sahibinin özellikleri, işletme özellikleri ve dış faktörler olarak ü̧̧ başlık altında incelenebilir. Ayrıca ihracal, uluslararasılaşma sürecinin ilk aşaması olduğundan çalıșmamızda uluslararasılaşmiı sürecinin de incelenmesine yer verilecektir.

\subsection{Uluslararasılaş̣ma Süreci}

Işletmelerin uluslararasılaşmasını açıklamaya çalışan çeşitli modeller geliştirilmiştir. Bu modeller, uluslararasılaşma süreci, ve özellikle ihracat, üzerine pratik

3 M.Tamer Müftủoğlu, Türkiye'de Küçük ve Orta Ölçekli Işletmeler- Sorunlar * Oneriler, Sevin

${ }^{4}$ Bilkey Waren J., "An Alternpted Integration of the Literature on the Export Behavior of Firms". Journal of International Business Studies, Spring/Summer 1978, Vol:9, No:1, s:33-46; Erwin Dichtl, M. Leibold, H.G. Kölmayr, S. Müller. "The Export Decision of Small and Medium Sized Firms: A Review", Management International Review', 1984, Vol:24, No:2, s:49-60; Kurt J Miesenbock., "Small Business and Exporting: A Literetute Review", International Small Business Journal, Jan.-Mar. 1988, Vol:6, No:2, s:42-61; Nils-Erik Aaby, Stanley F. Slater, "Management Influence on Export Performance: A Review of the Empirical Literature 1978-88". International Marketing Review, 1989, Vol:6, No:4, s:7-26; Harold D.Morelend, "A Summary of the Internationalization Process of Smaller Enterprises and the Related Literature", Department of Business Studies, University of Edinburg, Working Paper Series, No:90/8, 1990, Edinburg, s:1-29.

5 Stan D. Reid, "The Desicion Maker and Export Entry and Expansion", Journal of Intenational Business Studles, Fall 1981, Vol:12, No:2, s:101. 
geçerliliği olan açıklamalarda yoğunlaşan modellerdir. Bunlardan davranış teorileri içinde ele alınabilecekler; aşamah olarak ihracau geliştirme modelleri ve yenilikçi modellerdir.

\subsubsection{Aşamalı Olarak Ihracatı Geliştirme Modelleri}

Bu modeller işletmelerde uluslararasılaşmayı yoğunluğu giderek artan ve birtakım kararlar serisini içeren faaliyetler zinciri olarak açılayan modellerdir.

Uluslararasılaşmayı aşamalı bir süreç olarak açıklamaya çalışanların öncüleri Jan Johanson ve Wiedersheim-Paul ${ }^{6}$ dür. Modelde, uluslararası faaliyetlerin büyük kaynak, pazar deneyimi ve bilgisi gerektirdiği, bu nedenle işletmelerin uluslararası faaliyetlere ancak yurtiçi piyasalarda geliştikten sonra ve göreceli olarak küçük olç̧ekte iken başladıklan ve uluslararası faaliyetleri, ani gelişmeler ve özellikle yatınm yaparak değil aşamalı olarak geliş̧irdikleri görüşü savunulmaktadır? ${ }^{7}$. Yazarlara göre işletmeler, yurtdışı pazar hakkındaki bilgi eksikliği nedeniyle belirsizlikten kaçınmak için ilk ihracat faaliyetlerine komşu ülkelerle veya daha iyi bildikleri ülkelerle veya pazarlarla başlayacaklardı ${ }^{8}$.

Bu modelde işletmelerin uluslararasılaşması için geçmeleri gereken 4 aşamadan bahsedilmektedir. Bu aşamalar şunlardır 9 .

1. Aşama: Ihracat yapmama

2. Aşama: Bağımsız acenteler ile ihracat yapma

3. Aşama: Yurtdışında sauş şubeleri kurarak ihracat yapma

4. Aşama: Yurtdışında yatırım /üretim yapma

Jan Johanson-Finn Wiedersheim Paul Modeli, Jan Johansan ve Jan-ErikVahlne ${ }^{10}$ tarafından yéniden ele alınmıs ve ilk modelin varsayımlan ve kavramları aynen kabul edilerek, bilgi eksikliği üzerinde duran, dinamik bir model geliştirilmiştir ${ }^{11}$. Yazarlara göre uluslararası faaliyetler hem genel bilgiyi hem de pazar bilgisini gerektirmektedir. Pazar bilgisi ancak deneyimler sonucunda elde edilebilir ve bu bilgi pazardaki fursatların ve problemlerin yönetici tarafından fark edilmesini sağlayarak yöneticinin; pazara yoğunlaşmasını, pazara ilişkin değerlendirmelere ve sonuçta mevcut kaynakların yurtdışı

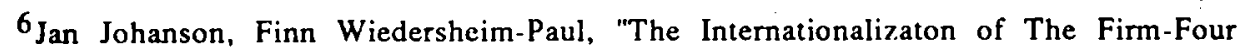
Swedish Cases", Journal Of Management Studies, October 1975, s:305-322.

7 Aynı eser, s:305.

8 Aynı eser, s:306.

${ }^{9}$ Aynı eser, s:307.

10 Jan Johansan, Jan-Erik Vahlne, "The Internationalization Process of The Firm-A Model of Knowledge Development and Increasing Foreign Market Commitments", Journal of International Business Studies, 1977, Vol:8, No:1, s:23-32.

${ }^{11}$ Otto Andersen, "On The Internationalization Process of Firms: A Critical Analysis", Journal of Intertanional Business Studies, 1993, Second Quater, Vol:24, No:2, s: 210 . 
faaliyetlere aktarımına ve pazaı bağlantılanna girilmesine ilişkin yeni kararlar almasına yol açar ${ }^{12}$. Işletmenin aldı̆̆ veni kararlar, işletmenin failiyetlerinde gelişmeye neden olmakta bu ise yeni pazar bağlantularına ve pazar bilgisine gerek duyurmaktadır. Sağlanan yeni bilgiler ve kaynaklar ile pazar bağlantılan ise işletme yöneticisinin yeni fırsatlan görmesini ve yeni kararlar alnasını gerektirmektedir. Bu sürę̧ ilerledikce işletme de ulusldararasılaşmada gerekli aşamalan geçmektedir.

Yukarda açıklanan iki model ululararasılaşma sürecini, karar verici olarak işletme sahibini ihmal ederek, sadece ileriye doğru tek yönlü bir kanallar zinciri ile açıklamaya çalışmaktadırlar. Bu eksiklik 'Warren Bilkey ve George Tesar ${ }^{13}$ tarafından geliştirilen modelde ortaya konmuştur. Yiazarların yapuğı çalışmada işletme sahibinin ozzellikleri ve dinamizmi uluslararasılaşmanıı en önemli unsuru olarak belirtilmiştir.

Model, uluslararasılaşma sürccini 6 aşamada açıklaunaktadır. Bu aşamalar ${ }^{14}$ :

1.Aşama: Yönetici ihraccatla ilgilenmemektedir.

2.Aşama: Yönetici ilk ihracat siparişini dış firmalardan almakıa fakat uygulama olană̆ını araşurmamakıdır.

3.Aşama:Yönetici ihracatın uygulanabilirliğini araşurmaya başlamaktadır. başlamaktadir.

4.Aşama: Işletme deneyime dayanan ilk ihracatını yakın ülkelere yapmaya

5.Aşama: Işletme deneyimli bir ihracatçı olarak o ülkedeki ihracaunı optimal düzeye çıkarmak için tarifeleri ve kurları değiştirmeye çalışmaktadır.

6.Aşama: Işletme bira: daha uzaktaki ülkelere ihracatın olabilirliğini araşurmaya başlamaktadır.

Ihracatta karar verici ılarak işletme sahibinin/ yöneticinin önemi Bilkey'in 1978 yılında yaptığı bir başka araştırmada ${ }^{15}$ daha belirgin bir biçimde ortaya konulmuştur. Bilkey bu çalışmasında, ihraçatın şu faktörlere bağlı olduğunu ileri sürmektedir:

-Yönetici bakı̧̧ açısınıı görc ihracatın çekiciliğ j,

-Işletmenin uluslarardsına yönelme derecesi (yöneticinin yurıdışı faaliyetlere karşı tutumu),

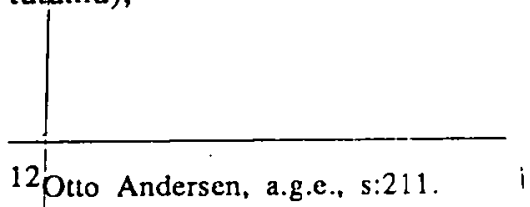

13 Warren J. Bilkey, George Tesar, "The Export Bchavior of Smaller-Sized Wisconsin Manufactiring Firms", Journal of International Business Studies, 1977. Spring/Summer, Vol:8, No:1, s:93-98.

14 Aynı eser, s:93.

15 Bilkey Warren J., a.g.e., s:33-46. 
-Yöneticinin işletmenin rekabet avantajlanna inancı,

-I̧̧ piyasadaki olumsuzluklar.

Uluslararasılaşmanın aşamalı olarak gelişimini davranışsal açıdan inceleyen son model Tamer Çavuşgi1 ${ }^{16}$ tarafından geliştirilmiştir. Cavuşgil, modelinde en onemli faktörün pazar araş̧ırması, pazarla ilgili verilerin sağlanması olduğunu vurgulayarak uluslararasılaşma sürecini işletmelerin verileri elde etme ve pazar araşurması çabalanna göre 5 aşamada açıklamaktadır. Bu aşamalar şunlardır.

1.Aşama: Iç pazara yönelik pazarlama:

Bu aşamada işletme sahibi ihracat konusunda bilgi sahibi değildir. Işletmenin tüm çabası yurt içi pazara yöneliktir.

2. Aşama: Ihracat öncesi aşama:

Bazı iç ve dış faktörler sonucu işletme sahibi ihracatla ilgilenmeye ve yapılabilirliği konusunda bilgi toplamaya yönelmektedir.

3.Aşama: Edinilen tecrübeyle ihracatta pasif yoğunlaşma:

Işletme sahibi ihracatı yapılabilir görürse kendisine yakın gördüğü birkaç ülkeye ihracata başlar.

4.Aşama: Ihracatta aktif yoğunlaşma: başlar.

Işletme yeni pazarlara girmeye ve toplam satışı içindeki ihracat oranını artırmaya

\section{Aşama: thracatta bağlantılar kurma:}

Bu aşamada uluslararası faaliyetlerde yeni engeller (ithalat sınırlamalan, taşıma olanaklan ve maliyetleri, kurlardaki oynamalar gibi) ortaya çıkmakta ve uzun vadede başarılı olunabilmesi için çeşitli bağlanular üzerinde yoğunlaşarak (yurtdışı ortaklıklar oluşturma, yurtdışı satış şubcleri açma veya yurtdışında imalata başlama) işletmenin uluslararasılaşması sürdürülebilmektedir.

\subsubsection{Yenilikçi Modeller}

Bu modellerde yenilik, işletmenin değişimlere uyum sağlaması olarak görülmekte ve ihracat, yeni bir ürün geliştirme gibi, işletmenin olağan faaliyetlerine ilave olarak, ilk defa başlayacağı, alışık olmadığı bir alana girmesi, başka bir değişle faaliyetlerde bir değişime neden olan faaliyet olarak görülmektedir.

16 S. Tamer Cavuşgil, "On the Internationalization Process of Firms", European Researh, November, 1980, s:273-281. 
Pazarlama yenilikçiliği olarak ihracat davranışı konusunda ilk çalışmayı Kenneth Simmons ve Helen Smith ${ }^{17}$ yapmıştır. $\mathrm{Bu}$ modelde yenilikçilik üç ana ợeye dayandırılmaktadır. Bunlardan birincisi, ilk ihracat faaljyetleridir. Yazarlara göre ilk ihracat faaliyeti, başka bir deyişle yenilikçilik, işlıtmenin i̧̧ dinamiklerinden kaynaklanmaktadır. Ikinci ana চğe, işletmede karar almadlan sorumlu kişi yenilikçidir. Yazarłlara göre yenilikçi, girişimci niteliklerine sahip kişidir. Bu kişi; işletme sahibi ya da işletme faaliyetlerini yürüten kişi olabilir. Bu kişiler rekabetçi, atılgan, yüksek risk üstlenebilen ve sürekli dış pazarlarda gezen kişilerdir. Modelin üçüncü ana oğesi ise, işletme faaliyetlerine egemen olan anlayışur. Yenilikçi modelde, sauş arturma yerine pazarlama anlayışı benimsenmektedir ${ }^{18}$. Bu durumda ihracat pazarına giriş, mevcut pazar potan'siyelinin değerlendirilmesinden sonra gerçekleşmektedir.

Yenilikçi Model kapsamında ele alınabilecek diğer bir çalışma da Lee ve Brash ${ }^{19}$ tarafindan yapılmışur. Bu model işletmelerin yeniliğe ujum sürecini, başka bir deyişle ihracat stratejisine uyum kararın incelemektedir. Bu modele göre işletmeler, ihracata iç piyașada karşılaştıkları sorunlar sonucunda değil, ancak yurtışı pazar fırsatlarından haberdar olduklarında başlarlar. Burada da en önemli görev karar vericiye düşmekte ve onun pazar fırsatları konusunda bilgi sağlaması gerekmıktedir. Ayrıca ihracat, belirli bağlantılar, kaynak aktarımı gerektirdiği ve risk içerdiği için karar vericinin rasyonel bir davranış göstereceği savunulmaktadır 20 .

Yenilikçi modeller içinde ele alınabilecek son model Stan D. Reid ${ }^{21}$ tarafından geliştirilen modeldir. Reid yeniliği benimseme sürecindeki aşamaları (haberdar olma, niyet, deneme, değerlendirme ve benimseme) ihracatı benimseme süreci olarak ele almiştır. Reid'e göre işletmeler, ihracat faaliyetlerine bir problemin veya bir fırsatun farkinda olarak başlarlar. Bu ise, ya yurtiçi pazardaki sorunun çözümü olarak yurtdışı pazar fırsatlarından haberdar olunması ile ya da işletmenin gelişmesi için yurtdışı pazarın potansiyel fırsat olduğunun anlaşılması ile olur. Karar vericinin ihracata karşı tutumu, inañışı ve motivasyonu uluslararası faaliyetlere yoğunlaşmayı etkileycrek işletmede ihracat yapma niyetinin doğmasına ve ihracat için bağlantı kurmaya ve kaynak aktarmaya itec'ektir. Haberdar olma ve niyet aşamaları, yurtdışından gelen bir taleple, fuarlarla ve yurtdışı pazarlan gezerek daha da güçlenecektir. Bu isee işletmenin ihracat faaliyetini denemesine neden olacaktır. Deneme aşamasının sonunda da ihracat sonuçlarının değerlendirilmesi yapılmaktadır. Eğer değetlendirme olumlu ise artık işletme yurtdışı pazarda kalabilmek için faaliyetlerde bulunacak ve işletmenin büyümesi için yeni bağlantılara girecektir ${ }^{2}{ }_{1}$

17 Keneth Simmons, Helen Smith, "The First Export Order: A Marketing Innovation", British Journal of Marketing. Summer 1968, s:93-100.

18 Ayn eser, s:95.

19 Lee Woo-Young, John J. Brasch, "The Adoption of Export As An Innovative Strategy", Journal of Intenational Business Studies, 1978, Vol:9, No:1, p:85-93.

20 Michael J. Thomas, Luis Araujo, "Theories of Export Behaviour: A Critical Analysis", European Journal of Marketing. Summer 1985, s:43.

21 Stan D. Reid, a.g.e., s:101-102.

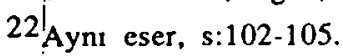




\subsection{Işletme Sahibinin Özellikleri}

Işletme sahibinin özellikleri ihracat davranışını ve dolayısıyla da karar alma sürecini doğrudan etkilemektedir ${ }^{23}$. Uluslararasılaşma modellerinde de işletme sahibinin özellikleri en onemli faktörlerin başında belirtilmektedir. Cavusgil ve Nevin ${ }^{24}$ yaptuklan çalışmada ihracat davranışının belirlenmesinde 4 unsur ileri sürmüşlerdir. Bunların üçü işletme sahibi ile ilgili unsurlardır:

-Işletme sahibinin ihracat konusunda işletmenin uzun vadeli büyüme amacı ile ilgili beklentileri,

-Işletme sahibinin kararlılı̆̆ı ve

-Işletme sahibinin arzusunun güçlülüğü.

Suzman ve Wortzel ${ }^{25}$ ise ihracatta başanlı olabilmek için işletmede çalışanlann hepsinin ihracatta kararlı olması gerektiğini savunmaktadırlar.

Erwin Dichtl, Hans-George Koeglmayr, Stefan Mueller ${ }^{26}$ işletme sahibinin uluslararasılaş̧maya yatkınlığı üzcrinde durmuşlar ve yaşlı, eğitim düzeyi düşük, yabancı dil bilgisi az, riskten kaçınan ve değişimi istemeyen, ihracata karşı olumsuz tutum içinde ve dış ülke deneyimi az olan işletme sahiplerini, uluslararasılaşmaya yatkın olmayan ve büyük olasılıkla ihracat faaliyetleri ile ilgilenmeyen işletme sahipleri olarak belirlemişlerdir.

Çavuşgil ve Naor ise ihracatın algılanı̧̧ı üzcrinde durarak, yaşın, eğitim düzeyinin, yabancı dil bilgisinin, yurtdışı deneyimlerinin ve bilgi toplama eł̆iliminin işletme sahibinin ihracatı algılayışında da ctkili olduğunu belirlemişlerdir ${ }^{27}$. Sood ve Adams ise özellikle bilgi toplama eğiliminin ve pazar bilgisine sahip olmanın ihracat karar sürecini olumlu yönde etkilediğini ortaya koymuşlardır ${ }^{28}$.

${ }^{23}$ Finn Wiedersheim-Paul, Hans C. Olson, Lawrence S.Welch, "Pre-Expont Activity: The First Step in Internatianalization", Journal of International Business Studies, 1978, Vol:9, No:1 spring/ summer, s:48.

${ }^{24}$ S. Tamer Cavuşgil, John R. Nevin, "Internal Determinats of Export Marketing Behaviour: An Empirical Investigation". Journal of Marketing Research, 1981, Vol:18, No:1, s: 115 .

25 Cedric Suzman, Lawrence Wortzel, "Technology Profile and Export Marketing Strategies", Journal of Business Research, 1984, Vol:12, No:2, s:89.

${ }^{26}$ Erwin Dichtl, Hans-George Koeglmayr, Stefan Mueller, "International Orientation as a Precondition for Export Success", Journal of International Business Studies, 1990, Vol:19, No:2, s:27.

${ }^{27}$ Tamer S. Cavuşgil, Jacob Naor, "Firm And Management Characteristics as Discriminators of Export Marketing Activity", Journa of Business Research .1987, Vol:15, s:223.

${ }^{28}$ James H.Sood, Patrick Adams, "Model of Management Learning Styles as a Predictor of Export Behavior and Performance", Journal of Business Research, 1984, Vol:12, $\mathrm{s}: 176$. 
thracat karar sürecinde elkili olan ve literatürde çok fazla üzerinde durulan bir diǧer işletme sahibi özelligyi de işletme sahibinin ihracata karşı tutumudur 29 .

\section{3.İşletme Özellikłeri}

Işletmelerin ihracat kararını etkileyen işletme özelliklerinden ölçek büyüklü̈̆ü literatürde en fazla üzerinde durulan faktördür, ancak ölçek büyüklügünün ihracata etkisi (olumlu veya olumsuz) konusunda bir görüş birliği yoktur ${ }^{30}$.

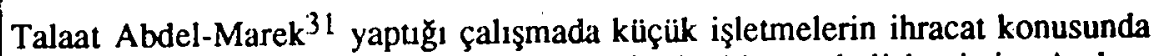
büyük işletmelere göre daha başarılı ve istekli olduklarını belirlemiştir. Andrea Bonadcorcorsi ${ }^{32}$ de benzer bir sonuca ulaşmıştır. Edmuns ve Khoury ${ }^{33}$ ise yaptuklan çalışmada 10 personelin altında çalışanı olan küçük işletmelerin, finansal ve insan gücü yeterli olmadığı için ihracat yapamadıklannı fakat diğer kụ̧̈ük ve orta ölçekli işletmelerin karlı bir şckilde ihracat yaptulilannı saptamışlardır. Çavuşgil ${ }^{34}$ araşırmasında işletme büyüklügü olarak çalışan sayısı alındığında ihracatla işleıme büyüklügü arasında istatiśtiksel olarak anlamlı bir ilişki saptayamazken, işletme büyüklügüu olarak satış tutarı alındığında işletmelerin ihracat davranışlarında farklar olduğunu ortaya koymuştur. Abbas ve $S$ wiercz ${ }^{35}$ de konuyı ihracata karşı tutum açısından ele almışlar ve küçük, orta ve büyük ölçekli işletmelerin ihracata karşı tutumlarında belirgin bir fark olmadığını

${ }^{29}$ Wesley J. Johnston., Michacl R. Czinkota, "Export Attitudes of Industrial Mánufacturing", Industrial Marketing Management, 1985, Vol:14, s:123-132; Abdolreza Eshghi, "Attitude- Behaviour Inconsistency in Exporting", International Marketing Review, 1992, Vol:9, No:3, S:40-61; Donald L.Brady, William O. Bearden, "The Effect of Managerial Attitudes on Alternative Exporting Models", Journal of International Business, Winter 1979, s:33-46; M.Frank Bradley, "Altitudes to Export Marketing Growth Among Small Scale Enterprises: A Discriminant, Analysis", Marketing:Future Imperfect, Proceedinģ of Marketing Education Group Annual Conference, Ed: Philip R. Flood,Campbell L. Grant, Aidan O'Driscoll, Vol:1, Dublin, July 1981, s:290-310; Delwin Roy, Claude L. Simpson, "Export Attitudes of Business Executives in The Smaller Manufacturing Firm", Journal of Small Business Management, April 1981, Vol:i9, No:2, S:16-22.

${ }^{30}$ Nils-Erik Aaby, Stanley F. Slater, a.g.e., s: 17.

${ }^{31}$ Talaat Abdel-Marek, "Export Marketing Orientation in Small Firms", American Journal of Small Business, 1978, Vol:3, NO:1, s:25.

32 Andrea Bonarccorsi, "On the Relationship Between Firm Size and Export Intensity". Journal of International Business Studies, 1992, First Quater, s:605-635.

${ }^{33}$ Stahrl E.Edmuns, Sarkis J. Khoury. "Exports:A Necessary Ingredient in the Growth of Sthall Business Firms", Journal of Small Business Management, October 1986. $V_{0}^{\prime} 1: 24$, No:4, s:56.

${ }^{34}$ Tamer S.Cavuşil, "Differences Among Exporting Firms Based on Their Degree of Internationalization", s:195-208.

35 Ali Abbas, Paul M. Swiercz. "Firm Size and Export Behavior: Lesson From the Midwest", Journal of Small Business Management, April 1991, Vol:29, No:2, s: 74 . 
saptamışlardır. Kirpalani ve Macintosh ${ }^{36}$, McGuinness ve Little $^{37}$, Çavuşgil ${ }^{38}$ ile Axin 39 ise orta ölçekli işletmelerin ihracata daha sistematik yaklaştıklarını belirlemişlerdir.

Cooper ve Kleinschmidt ${ }^{40}$ oblçek büyüklüğü ile ihracat arasında negatif bir ilişki olduğu sonucuna ulaşırlarken, Czinkota ve Johnson ${ }^{41}$ ilc Diamantopoulos ve Inglish ${ }^{42}$ ise olçek büyüklügü ile ihracat arasında bir ilişkinin olmadığını ileri sürmüşlerdir.

Işletme ózelliği olarak literatürde üzerinde durulan diğer bir faktör de işletmenin yaşı ve deneyimleridir. Kirpalani ve Machintosh ${ }^{43}$ işletme yaşı ile ihracat arasında ters yönlü bir ilişkinin olduğunu vurgulamaktadır. Buna göre yaşlı işletmeler ihracatta daha az başarılı olmaktadır. Cooper ve Kleinschmidt ${ }^{44}$ de benzer şckilde genç işletmelerin ihracatta daha başarılı olduğunu saptamışur. Madsen ${ }^{45}$ ise başarılı bir ihracat pazarlaması yönetimi için ihracat deneyiminin gerekliliğini ileri sürerek işletmelerin ihracat performansını belirlerken bu faktörün çok önemli olduğunu vurgulamaktadır. Fakat Çavuşgil ${ }^{46}$ ihracat deneyiminin uluslararasılaşmayı açıklamada çok gerekli bir faktơr olmadığını savunmaktadır.

\section{Ihracat Karar Sürecine İlişkin Model Denemesi}

Ihracat karar süreci, işletme sahibi özellikleri ile işletme özellikleri ve bunlar arasındaki etkileşimi ve dış faktörlerden etkilenmeleri sonucunda oluşan karmaşık bir

${ }^{36}$ V.H.Kirpalani, N.B. Macintosh, "International Marketing Efectiveness of Tecnology oriented Small firms". Journal of International Business Studies, Winter 1980, s:81-90.

${ }^{37}$ Norman W. McGuinness, Blair Little, "The Influence of Product Characteristics on the Export Performance of New Industrial Products", Journal of Marketing. Spring 1981, Vol:45, s:110-122.

${ }^{38}$ S. Tamer Cavuşgil, "Organizational Characteristics Associated with Export Activity", Journal of Managemet Studies, 1984, Vol:21, No:1, s:3-21.

${ }^{39}$ Catherine N. Axinn, "Export Performance: Do Manegerial Perceptions Make A Difference?". International Marketing Review, Summer 1988, s:61-71.

40 Robert G. Cooper, Kleinschmidt J. Elko, "The Impact of Export Strategy on Export Sales Performance", Journal of International Business Studies, Spring 1985. s:37-55.

${ }^{41}$ Czinkota Michael R., Wesley J. Johnson, a.g.e., s:147-153.

42 Adamantios Diamantopoulos, Karen Inglish, "Identifying Differences Between High and Low Involvement Exporters", International Marketing Review, Summer 1988, s:52-60.

${ }^{43}$ V.H.Kirpalani, N.B. Macintosh, a.g.e., s:81-90.

${ }^{44}$ Robert G. Cooper., Elko J. Kleinschmidt, a.g.e., s:37-55.

${ }^{45}$ Tage Koed Madsen, "Successful Export Marketing Management: Some Empirical Evidence", International Marketing Review, 1989, Vol:6, No:4, s:41-55.

${ }^{46}$ Tamer S.Cavuşgil, "Differences Among Exporting Firms Based on Their Degree of Internationalization", s:195-208. 
süreç olarak belirlenmişti ${ }^{47}$. Ayrıca küçük ve orta ölçekli işletmelerde karar verici olarak işletme sahibinin ihracat kararındaki onnemi belirlenmişti. Bu nedenle ihracat karar süreci için model geliştirilirken işlctme sahibinin ozelliklerinin ağırlıklı olarak ele alınması gerekmektedir.

Geliştirilecek modelde, ihracata karar vermenin işletmenin faaliyet türünde feşitlendirme yapacağ ${ }_{1}$ ve işletme çevresini değiştireceğ ${ }^{48}{ }^{4}$, başka bir deyişle işletme ve girişimci açısından yeni bir faaliyet alanı olacağı için, ihracat, Kenneth Simmons ve Helen Smith ${ }^{49}$, W. Y. Lee ve J. J. Brash ${ }^{50}$, Reid'in ${ }^{51}$, modellerinde oldugu gibi yenilik olarak ve ihracata karar alma sürcci de yeniliği benimseme süreci olarak ele alınacaktur.

Ihracat karar süreci, ihracat konusunda bilgi edinmeyle başlayıp benimseme veya benimsememe kararına uzanan bir mantık süreci olduğu için girişimcinin ihracat fikrini keşfétmesi ve haberdar olması, pazar araştırması ve bilgi toplama faaliyetleri, değerlendirme ve ihracata karar verne ile sonuçlanır 52 .

Biz de ihracatı yenilik olarak ele aldığımız ve ihracat karan alma sürecini de yeniliği benimseme süreci olarak inceleyeceğimiz için Reid ${ }^{53}$ ve Jatusripitak ${ }^{54}$ çalışmalanndakine benzer şekilde ihracat karar sürecinin belirli aşamalardan oluştuğunu kabul ediyoruz. Kanaatimizce bu aşımalar aşă̆ıakaki şekilde belirlenebilir:

1.Aşama: Harekete Geçirici Motivasyon

2.Aşama: thracaun Işlıttme Için Öneminden Haberdar Olma

\section{Aşama: Pazarlama Arraştırması ve Bilgi Edinme}

\section{Aşama: Değerlendirne}

\section{Aşama: thracata Karar Venne}

Aynca Finn Wiedersheim-Paul, Hans C. Olson, Lawrence S. Welch ${ }^{55}$ ve Hans Christer Olson ve Finn Wiederssheim-Paul ${ }^{56}$ modellerinde olduğu gibi küçük ve orta ${ }^{47}{ }^{1}$ tan D. Reid, a.g.e., s:101.

${ }^{48}$ S. Tamer Cavuşgil, Yezdi M. Godiwalla, "Decision-Making for Interntional Marketing: A Comparetive Review", Management Decision, 1982, Vol:20, No:4, s:47.

${ }^{49}$ Keneth Simmons, Helen Smith, a.g.e., s:93-100.

${ }^{50}$ Lee Woo-Young, John J. Brasch, a.g.e., s:85-93.

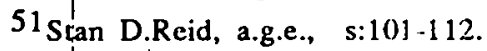

52 Somkid Jatusripitak. The Expor1 Behavior of Manufacturing Firms, UMI Research Press, Michigan, 1986, s:24.

53 Stan D.Reid, a.g.e., s: 103.

54 Somkid Jatusripitak,a.g.e., s:25.

55 Finn Wiedersheim-Paul, Hans C. Olson, Lawrence S.Welch, a.g.e., s: 47-58.

56 Hans Christer Olson, Finn Wiedersheim-Paul, "Factors Affecting The Pre-Export Behaviour of Non-Exporting Firms", European Resaerch In International 
olçekli işletmeler için önemli aşamalar ihracata başlamaya karar vermenin ilk aşamaları olduğu için, ăğırlıklı olarak, varsaydığımız ihracat karan alma sürecinin aşamalanndan sadece ilk üçü üzerinde durulacaktur.

\subsection{Harekete Geçirici Motivasyon}

Davranış teorilerine göre, işletmenin ve/veya kişinin bir davranışta bulunması, bir ihtiyacın doğması veya belirli bir amacı gerçekleştirebilmek için bir güdünün oluşması ile gerçekleşmektedir. Bu açıdan işletme sahibinin ihracau benimsemesinde de başlatıcı faktörler çok ơnemli rol oynamaktadırlar ${ }^{57}$. Bu çalışmada ihracata başlatıcı faktörler olarak, Lee ve Brasch ${ }^{58}$ 'n modelinde de ele alındığı gibi, problem kaynaklan ve dış pazar fırsatlarının görülmesi ele alınacaktır. Problem genellikle iç pazar şartlarından kaynaklanmaktadır. Ömeğin, iç pazann daralması, iç pazarda rekabetin artması ve işletmede atıl kapasitenin ortaya çıkması gibi. Dış pazar fırsatlarının farkedilmesi de işletme içi dinamiklerden kaynaklanmakta ve işletme gelişmesinin bir ifadesi olarak görülmektedir ${ }^{59}$. Kenneth Simmons ve Helen Smith ${ }^{60}$ modellerinde, ikinci grup başlatıcı faktörlerden etkilenen işletme sahiplerini girişimci, yenilikçi olarak adlandırmalarına rağmen, başlatıcı faktörlerin sadece girişimci tarafından algılandığı zaman etkili olacaklannı ${ }^{61}$ göz önünde bulundurarak, çalışmamızda yenilikçi girişimciyi bu başlaucı faktörlerden herhangi birini algılayan işletme sahibi olarak ele almaktayız. Zira aynı sektördeki girişimciler aynı başlaucı faktörlerle karşı karşıya olmalarına rağmen davranı̧̧ şekilleri faklılıklar gösterebilmektedir. Bu ise işletme sahibinin faktörleri algılamalanndaki farklılıklardan kaynaklanmaktadır.

\subsection{Ihracatın Iş̧letme Için Öneminden Haberdar OIma}

Iç pazarda problemle karşılaşan işletme sahibi sorundan kurtulmak için araşurmalar yaparak olası çözüm yollarından haberdar olur. Aynı şekilde dış pazar fırsatlarını görcn girişimci de bu pazardan yararlanmak için çeşitli yöntemleri araşurarak onlardan haberdar olur. Küçük ve orta ölçekli işletmeler için ise bu yöntemlerden dış pazara açılmada en etkili ve ilk yol, başlangı̧̧a da belirtildiği gibi, ihracattır.

Business, Ed:Micheal Gretman, James Leontiades, Nort-Holland Publishing Company, Amesterdam, 1978, s:283-299.

57 Jatusripitak Somkid, a.g.e., s:26,

${ }^{58}$ Lee Woo-Young, John J. Brasch, a.g.e., s:87.

${ }^{59}$ Canon T., McAuley A., McKay J., "Internationalization and the Role of Marketing", Scottish Enterprise Foundation, Occasional Paper Series, No:25/88, August 1988, s:3.

${ }^{60}$ Simmons Keneth, Helen Smith, a.g.e., s:93-100.

${ }^{61}$ Holzmüller Harmut H., Helmut Kasper, "On a Theory of Export Performance: Personel and Organizational Determinants of Export Trade Activiyies Observed in Small and Medium-Sized Firms", Management International Review, 1991, Vol:31, Special Issue, $s: 48$. 
ihracattan haberdar olan işletme sahibi, ihracatın işletmenin amaçlarını gerçekleştirmesi konusunda bir beklentisi varsa ihracat benimseyecektir ${ }^{62}$. Bu beklenti ise işiletme sahibinin ihracatı algılayış şekli, dış pazara yatkınlığı, işletme sahibinin objektif ve sübjektif özellikleri, ihracata karşı tutum, psikolojik uzaklık ve diğer işletmielerin başansının gözlemlenmesi ile belirginleşmekledir.

Işletme sahibi için yeni olan ihracat faaliyetinin risk derecesinin algılanışı, algılanan belirsizlik derecesi ve algılanan karmaşıklık derecesi ihracat karannı doğrudan etkileyecektir ${ }^{63}$. Ayrıca ihracaun, iç pazardaki faaliyetlere göre daha avantajlı olduğunun, işletmenin yurt içi faaliyetleri ve amaçlan ile uyumlu olduğunun ve işletme sahibi tarafindan ihracatın yapilabilecek bir faaliyet olarak algılanması da ihracat karannı etkilemektedir ${ }^{64}$. Ihracat konusunda algllanan risk derecesi ile ihracattan beklenen kar ve algılanan ihracatın maliyet derecesi ile fayda beklentisi arasındaki ilişki işletme sahibinin ihracat kararını belirlemektedir. Bu açıdan ihracat karar süreci algılanan risk ile beklenen kann bir fonksiyonudur da diyebiliriz ${ }^{65}$.

Dış pazara yatkınlığı, girişimcinin ihracatı başlatmak veya yoğunluğunu artırmak için kaynakları harekete geçirme isteği ve yapma kararlığı olarak tanımlayabiliriz ${ }^{66}$. Bu karaŕlılı̆̆ı ve kaynak aktarımını yurtdışına yapılan gezilerin sıklığı büyük ölçüde belirlemektedir.

Ihracat karar sürecine etki yapacak sübjektif özellikler olarak, işletme sahibinin kararlılığı, değişime istekli olması ve geleceğc bakışı olarak cle alınabilir ${ }^{67}$. Işletme sahibinin amaçlarına ulaşma veya sorunları çözmedeki kararlı davranışı ihracat kararında da kendisini göstermektedir. Aynı şckilde karşılaştığı durumlara kolayca kendisini uydưrması ve olumsuz gelişmeler karşısında olası çözümleri araşurma ĕgiliminde olması, ihracata da ister algılanan problemilerden olsun ister algılanan firsatlardan olsun hemen tepki göstereceğini ve ihracat kararını değgerlendireceğini kabul edebiliriz.

Işletme sahibinin objektif özellikleri olarak, yaşı, eğitim düzeyi, yabancı dil bilgisi ve dış gezilcrinin sayısı ele alınmaktadır ${ }^{68}$. Bu tür özcllikler işletme sahibinin dıs

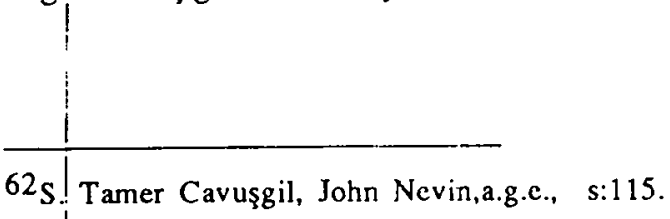

${ }^{63}$ Elyette Roux, "Managers' Altitudes Towards Risk Among Determinants of Export Entry of Small and Medium-Sized Firms". Managing Export Entry and Expansion, Ed:Philip J. Rosson, Stanley Reid, Praeger Publishers, New York, 1987, s:95.

${ }^{64}$ Catherine N. Axinn, a.g.e., s:64.

65 Delwin A. Roy, Claude L. Simpson, "Export Attitudes of Business Executives in the Stmaller Manufacturing Firm", Journal of Small Business Management, April 1981 , s: 18 .

${ }^{66}$ Talaat Abdel-Malek, a.g.e., s:25.

${ }^{67}$ Erwin Dichtl, M. Leibold, H.-G. Kögmayr, S. Müller, "The Export Decision of Small and Medium Sized Firms: A Review", a.g.e., s:56.

${ }^{68}$ Erwin Dichtl, M. Leibold, H.-G. Kögmayr, S. Müller, "International Orientation as a Precondition for Export Succe.s", a.g.e., s:31. 
pazar bilgisi ve etkin dıs pazar seçiminde etkili oldukları ${ }^{69}$ için karar alma sürecini hizlandirabilirler.

Işletme sahibinin ihracata karşı tutumu, ihracat davranışını ve dolayısıyla ihracat karar sürecini belirleyen bir faktördür ${ }^{70}$. Ihracata karşı tutumla ihracat davranışı her zaman paralellik göstermeyebilir. Örneğin girişimci ihracata karşı olumlu tutum içinde olmasına rağmen ihracat yapmamaktadır. Bu girişimcinin ihracat konusunda algıladığı risk ve belirsizlikten kaynaklanabilir. Aynı şekilde ihracatın işletme için öneminden haberdar olan işletme sahibi ihracata karşı olımlu tutum içinde olmasına rağmen nereye ve nasıl ihracat yapacağını bilmediğinden tutum, davranışa dönüşememektedir. Ihracata karşı olumsuz tutum ise gencllikle ihracatun algılanışı ile ilgilidir ${ }^{71}$. Ihracata karşı tutumun olumlu olması ise girişimcinin ihracattan beklentisini olumlu olarak etkilemektedir.

Psikolojik uzaklık kavramı, Johanson ve Wiedersheim-Paul ${ }^{72}$, Johanson ve Vahlne ${ }^{73}$ modellerinde ele alındığı gibi dil, kültür, endüstriyel gelişmişlik ve sosyal ortam bakımından birbirinden farklı olan pazarların yanında coğrafi uzaklığı da içermektedir. Finn Wiedersheim-Paul, Hans C. Olson, Lawrence S. Welch ${ }^{74}$ tarafindan da belirtildiği gibi küçük ve orta ölçekli işletmeler ihracata kendilerine psikolojik olarak yakın gördükleri ülkelerden başlamaktadırlar. Bu nedenle girişimcinin dı̧ pazara yatkınlı̆̆ı ve ihracat kararı alma sürecinde psikolojik uzaklık kararı etkilemekte ve yönlendirmektedir.

Yeniliği benimsemede diğer önemli bir nokta da girişimcinin kendine güvensizliği veya kendisini yetersiz görmesi nedeniyle yenilikten kaçınmasıdır. Ayrıca rutin faaliyetlerin verdiği rahatlık da burada önemli rol oynamaktadır. Bu da ancak başkalannı izleyerek aşılabilmektedir ${ }^{75}$. Ihracau ilk benimseyenlerden sonra onlan takip edenler için artık risk, belirsizlik ve araştırma maliyeti daha az olacaktır. Aynca ihracat yapan işletmenin performansını gören girişimcinin ihracat konusundaki algılaması ve tutumunu değişecek ve beklentileri oluşmaya başlayacaktır ${ }^{76}$. Bu nedenle ihracat karan alma sürecinde diğer işletmelerin performansı da ctkili olmaktadır.

\subsection{Pazar Araştırması ve Bilgi Edinme}

Ihracatın işletme için öneminden haberdar olan ve yukarda belirtilen faktörler sonucunda ihracat konusunda beklentileri oluşan işletme sahibi bilgi toplama aşamasına geçeccktir. thracat için bilgi toplamak ve pazar bilgisi önemli olmakla birlikte bilgi

${ }^{69}$ Stan D. Reid, "Managerial and Firm Influences on Export Behavior", 1983, Journal of The Academy of Marketing Sciences, Summer 1983, Vol:11, No:3, s:324.

${ }^{70}$ Somkid Jatusripitak, a.g.e., s:27.

71 Abdolreza Eshghi, a.g.c., s:50.

72 Jan Johanson, Finn Wiedersheim-Paul, a.g.e., s:305-322.

$73 \mathrm{Jan}$ Johansan, Jan-Erik Vahlne, a.g.e., s:23-32.

${ }^{74}$ Wiedersheim-Paul Finn, Hans C. Olson, Lawrence S.Welch, a.g.e., s:47-58.

${ }^{75}$ Somkid Jatusripitak, a.g.e., s:36.

${ }^{76}$ Aym eser, s:37. 
araşưrması işletme sahibinden işletme sahibine färklılık gőstermektedir. Bu fark da, işlețme sahibinin verilerin faydal/ ${ }_{1}$ ̆ $_{1}$ konusundaki düşünceleri ${ }^{77}$, algılanan belirsizlik ve risk derecesi ${ }^{78}$ ve ihracatın işletme için ne kadar önemli olduğunun anlaşılmasına ${ }^{79}$ göre ortaya çıkmaktadir.

Belirsizlik ve risk ihracaıtıa iç pazarda faaliyet göstermeye göre daha fazladır. thracatın belirsizliłginin algılanış derecesi ve algılanan risk derecesi de bilgi eksikliğinden kaynaklanmaktadır ${ }^{80}$. Yaplan araşturmalar ise belirsizlik içinde karar almak durumunda I olan girişimcinin, belirsizlik alanını daralımaktadır 81 . Zira dıs pazar ve ihracat konusunda yeterli bilgi sağlanması durumdiı algılanan belirsizlik ve risk azalırken ihracata karşı tutumlar da deģişmektedir. Bu durumđa ihracata karşı tutum ve ihracatın algılanışı ihraçattan beklentileri arturarak işletme sahibini bilgi toplamaya yőneltirken, aynı şekilde toplánan bilgi de algı ve tutumu hracat lehine etkilemcktedir. Bu açıdan da girişimcinin bilgîlerden ve bilgi edinme kanallarından haberdar olması ihracat karar süreci için çok onemli bir faktördür 82 .

\section{4. İhracat Karar Süreci Model Denemesi}

Yukardaki açıklamalar çerçevesinde ihracat karar süreci modelini şu şekilde belinleyebiliriz:

-Işletme sahibinin iç pazı́r koşullarını ve dış pazar fırsatlarını algılayış şekli ve ihraçata genel olarak bakış açısı, onu ihracat konusunda bcklentilere götürmektedir.

-Işletme sahibinin ihracati karşı tutumu da ihracat konusundaki beklentileri ortaya çıkarmaktadır. Aynca ihracatın .lılgılanışı ihracata karşı tutumu, ihracata karşı tutumda ihraçatın algılanışını etkilcmektedir. Bu etkileşim sorıucunda oluşan olumlu tutum girişimciyi ihracat konusunda bilgi toplamaya ve araştırmaya yöncltecektir.

-Ayrıca diğer işletmelerin ihracat konusundaki başanlan işletme sahibinin ihracata karşı tutumu ve algılayışını etkilı:mektedir.

-Işletme sahibinin objekt if ve sübjektif özellikleri de hem ihracat konusundaki beklentilerin oluşmasında rol oynarken hem de bilgi toplama ve araşurma eğilimini ortaya koyacaktur.

77 MicAuley Andrew, "The Percieved Usefulness of Export Information Sources", European Journal of Marketing, 19!13, Vol:27, No:10, s:52-64.

78 Wesley J. Jhonson, Michael R. Crinkota, a.g.e., s: 124.

${ }^{79}$ Somkid Jatusripitak, a.g.e., s: 29 .

${ }^{80} \mathrm{~A}$. Diamantopoulos, B.B. Schiegelmilch, C. Allpress, "Export Marketing Research in Practice: A Comparison of User and Non-Users", Journal of Marketing Management, 1990, Vol:6, No:3, s:257.

81 düney Devrez, Piyasa Araştırmalarında Bilgi Toplama Metotları, Sevinç Matbaası, Ankara, 1971, s:9.

82 Rolf Seringhaus, "The Role of Information Assistance in Small Firm's Export Ihvolvement". International Small Business Journal, Winter 1986/1987. Vol:5, No:2, s: 26. 
-Ihracat yapılabilecek ülkelerin işletme sahibi açısından algılanan psikolojik uzaklığı da karar sürecini etkilemektedir.

-Bilgi toplama ve araşurma sonucunda oluşacak yeni tutum biçimleri ve. ihracat konusundaki beklentiler işletme sahibini ihracat karan almaya yönlendirecektir.

thracat karar sürecinin şekil olarak gösterimi aşağıda verilmiştir. 


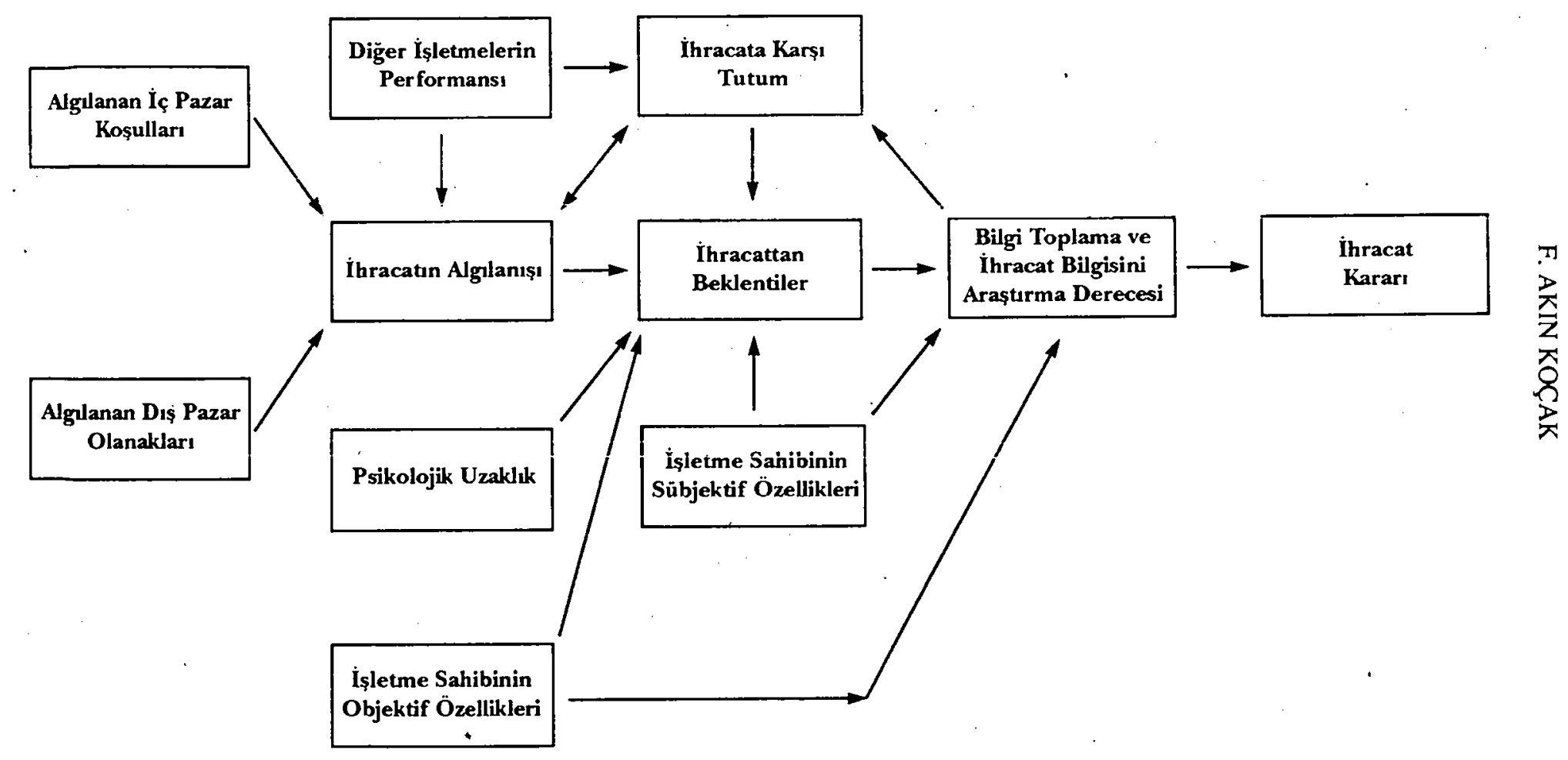




\section{Türkiye'deki Küçük ve Orta Ölçekli İşletmelerde Modelin Denenmesi ${ }^{83}$}

\subsection{Araştırmada Kullanılan Yöntem}

Ihracat davranışı literatüründe ele alınan ihracat karar süreci faktörleri çerçevesinde bu çalışmada geliştirdiğimíiz modele göre, Türkiye'deki küçük ve orta ölçekli sanayi işletmeleri yaptığımız bir alan araştırması çerçevesinde değerlendirilmiş̧ir. Bu amaçla, Türkiye genelinde küçük ve orta ölçekli sanayi işletmelerinin yoğun olarak faaliyette bulunduğu 11 il (Istanbul, Bursa, Izmir, Balıkesir, Denizli, Eskişehir, Ankara, Kayseri, Çorum, Gaźiantep ve Şanlıurfa) ve dört sektör (Gıda, Dokuma ve Giyim, Makina ve Plastik) belirlenerek araşurmaya temel alınmışur.

Araştırma verileri, 11 ilde tesadüfi örnekleme yoluyla uygulanan bir anket aracılığıyla derlenmiştir. Yapılacak değerlendirmelerin \%95 güven aralığında 0.05 ve daha az hata içermesi kabul edilebilir görülmüş, bu açıdan anket uygulanacak işlețme sayısı 400 olarak hedeflenmiştir. Fakat cevaplandırılmama olasılığı da dikkate alınarak 600 işletmeye anket formu gönderilmiştir. Cevaplandırılan anket sayısı, hedeflenen (400) sayının biraz altunda kalmış, 362 işletmeden cevap alınabilmiştir. (Cevaplandınıma oranı gönderilen anket formu sayısına göre \%60, hedcflenen sayıya göre \%90.5). Bu durumda da yine yapılacak değerlendirmeler $\% 95$ güven aralığında 0.05 hata içermektedir. Örneklemin büyüklüğ̈̈ (362 işletme) seçilen il ve sektörlerdeki toplam işletmelerin (70704) 0.0051 'ini oluşturmaktadır.

Soru formlarından clde edilen verilerin değerlendirilmesi bilgisayar aracılı̆̆ı ile yapılmıs, SPSS paket programından yararlanılmıştır. Değerlemede, istatistik yöntemlerinden bağımlılık testi kullanılmışır.

Araştırma kapsamına 11 ilde, 4 sektörde faaliyct gösteren küçük ve orta ölçekli sanayi işletmeleri alınmış, işletme büyüklüklerinin belirlenmesinde çalışan personel sayısı ölçütü kullanılmışıır.

Küçük ve orta ölçekli işletmeler arasında da bir ayrıma gidilerek ihracat potansiyeli çok az olarak düşünülen mikro işletmeler (çok kü̧̧ük işletme) çalışma kapsamının dışında bırakılmış, diğer işletme büyüklüklerinde ise daha ayrıntılı bir inceleme yapabilmek için 4'lü bir ayrıma gidilmiştir. Bu ayrıma göre işletme büyüklükleri 84 ;

$(10-19$ $(100-250)$ personel çalıştıran sanayi işletmesi personel çalışıran sanayi işletmesi personel çalıştıran sanayi işletmesi personcl çalıştran işletme
: Küçük Işletme

: Küçük/orta Ölçckli Iş̧letme

: Orta Ölçckli Işılctme

: Orta/büyük Ölçekli Işletme

şcklindedir.

${ }^{83}$ F.Akın Koçak, "Davranışsal Açıdan Türkiyeíde Küçük ve Orta Olçekli ışletmelerin ıhracat Pazarlaması Karar Alma Süreci", Yayınlanmamı̧ Doktora Tezi, Ankara Iniversitesi Sosyal Bilimler Enstitüsü, Ankara, 1997.

${ }^{84}$ VakıfBank, KOBl'lerde Ihracat Pazarlaması ve Ihracatın Finansmanı, VakıfBank Araştırma Dizisi 5, 1994; Ankara, s:2. 


\subsection{Kullanılan Değişkenler}

Geliştirilen modeldeki faktörlere ilişkin değişkenler şunlardır:

-thracaun algılanışı; risk, maliyet ve karlılık gerçevesinde incelenmiştir.

-Işletmeye ilişkin özellikler; ölçek büyüklügüü, faaliyet alanı, işletme yaşı, bulunduğu bölge ve bulunduğu il olarak belirlenmiştir

-Işletme sahibine ilişkin özellikler; yaş, eğitim düzeyi, yabancı dil bilgisi, yurtdışına yatkınlık (yurtdışına çıkma sıklığı) ve değişime yatkınlık olarak belirlenmişsir.

-Bilgi toplama ve araştırma eğilimi; fuarlara katılma, eğitim ve seminerlere kathım ve danışmanlık şirketlerine başvurma çerçevesinde incelenmiştir.

\subsection{Değerlendirme}

Çalışmamızda geliş̧irilen ihracat karar süreci modelindeki değişkenlerin Türkiye ozzelinde incelenmesinde; Türkiye'deki küçük ve orta ölçekli işletmelerin ihracat kararına bu déğişkenlerin etki oranlan bağımlıık testine göre şu şekilde belirlenmiştir:

Türkiye'deki küçük ve orta ölçckli işletmeler ihracata algılanan dış pazar fırsatlan ile başlamaktadırlar. Ihracat karan üzerinde en önemli etkiyi işletme sahiplerinin fuarlara katılma eğilimi ve bununla paralel olarak yurtdışına yatkınlık, yurt dışına çıkma sıklı̆̆ı yapmaktadır. Ölçek büyüklüğğ de ihracat kararında önemli bir ağırlığa sahiptir. Ağırlığı azalmakla birlikte, işletme sahiplerinin eğitim düzeyi ve yabancı dil bilgisi, işletmenin yaşı, işletme deneyiminin ve son olarak da ihracata karşı tutumun ihracat karar sürecinde etkisi olan faktơrler arasında yer aldığı görülmüştür. Ihracat karar süreci oluşturulurken ihracăt karan üzerinde önemli olarak düşündüğümüz işletme sahibinin yaşı ile algılanan karlı!ık ve maliyetin ihracat karan üzerinde etkili olmadıklan anlaşılmışı̆. Yine karar süreci oluşturulurken üzerinde durulan işletme sahibinin değişime yatkınlığının da ihracat karañ üzerinde çok önemli bir etkisinin olmadığı belirlenmiştir. Bu durumda büyük bir olasılıkla, küçük ve orta ölçekli işletme sahiplerinin, doğasında var olan girişimcilik nedeniyle, ihracat yapsalar da yapmasalar da değişime yatkın olmalanndan kaynaklanmaktadır (Tablo 1) ${ }^{85}$. 
Tablo 1

Ihracat Karar Sürecindeki Değişkenlerin thracat Üzerindeki Etki Oranları

\begin{tabular}{|c|c|c|}
\hline \multicolumn{2}{|l|}{ thracat Karar Sürecindeki Değişkenler } & \multirow{2}{*}{$\frac{\text { Etki Oranı }}{=0.13}$} \\
\hline Işletme sahibine ilişkin özellikler & - algulanan iç pazar koşullanı & \\
\hline & - algılanan dış pazar koşullan & 0.60 \\
\hline \multirow[t]{5}{*}{ Işletmeye ilişkin özellikleri } & - ölçck büyüklüğü & 0.44 \\
\hline & - faaliyet alanı & 0.20 \\
\hline & - işletmenin yaşı & 0.30 \\
\hline & - bulunduğu bölge & 0.20 \\
\hline & - bulunđuğu il & 0.27 \\
\hline \multirow{4}{*}{$\begin{array}{l}\text { Işletme sahibine ilişkin özellikler } \\
\text { Objektif özellikler }\end{array}$} & . & \\
\hline & - yas & 0.00 \\
\hline & - cğitim düzeyi & 0.38 \\
\hline & - yabancı dil bilgisi & 0.32 \\
\hline \multirow[t]{2}{*}{ Sübjektif ozellikler } & - yurtdışına yatkınlık & 0.44 \\
\hline & - değişime yatkınlık & 0.13 \\
\hline \multirow[t]{3}{*}{ thracaun algılanısıı } & - risk & 0.25 \\
\hline & - maliyet & 0.00 \\
\hline & - karlılık & 0.00 \\
\hline Ihracata karşı tutum & & 0.30 \\
\hline \multirow[t]{3}{*}{ Bilgi toplama ve araşıruma eğilimi } & - fuarlara katılma & 0.47 \\
\hline & - eğitim ve seminerlere katulım & 0.25 \\
\hline & - danışmanlık şirketlerine başvurma & 0.19 \\
\hline
\end{tabular}

\section{Sonuf}

Türkiye'deki küçük ve orta ölçekli işletme sahipleri, konunun literatürde ele alınışına paralel olarak, dıs pazar fırsatlarından haberdar olarak ihracata başladıkları için yenilikçi, girişimci ozelliğindedirler. Bu da işletme sahiplerinin ihracata karşı olumlu 
tutum içinde olduklarını ve potansiyel ihracatçı olduklarının göstergesidir. 'Bu ihracat potansiyellerini değerlendi ebilmek için işletme sahiplerinin bilgi toplama ve araşturma eğilimlerinin artırılması, yurtdışına sıkça çıkmalannın ve özellikle fuarlara kauılmalannın sağlanması gerekmektedir. Bu, küçük ve orta ölçekli işletmelerin algıladıklan riski büyük ölçüde azaltacakur. Zira isłletme sahipleri yurtdışı pazarlarını yakından izledikleri için oralardaki fırsatlardan habeıdardırlar. Fakat onlar için gerekli olan bu bilginin o pazarlarda uygulama olanağının sağlanması, başka bir değişle o pazarlara ulaşabilmeleridir. Ayrıca işletme sahiplerinin eğitim düzeyini ve yabancı dil bilgisini artırıcı çalışmalar yapılması ihraçat arurma üzerinde etlili olacaktır.

Tüm bu çalışmalarıı yapılması işletme sahiplerinin ihracat olanaklarını araşurma ve ihracata yönelme eğilimlerini artıracakur. Böylece de parasal teşviklerle sağlanan fakat kısa süreli olan ihracat sıçrıması sürckli hale gelmiş olacaktır.

\section{KA YNAKÇA}

Aaby Nils-Erik, Stanley F. Slater, "Management Influence on Export Performance: A Review of the Empirical Litcrature 1978-88", International Marketing Review, 1989, Vol:6, No:4.

Abbas Ali, Paul M. Swiercz, "Firm Size and Export Behavior: Lesson From the Midwest", Journal of Small Business Management, April 1991, Vol:29, No:2.

Abdel-Malck Talaat, "Export Marketing Oricntation In Small Firms", America Journal of Snall Business, 1978, Vol:3, No:1.

Andersen Otto, "On The Internationalization Process of Firms: A Critical Analysis", Journal of Intertanional Business Studies, 1993, Second Quater, Vol:24, No:2,

Andrew McAuley, "The Pcrcieved Uscfulness of Export Information Sources", European Journal of Marketing, 1993, Vol:27, No:10.

Axinn Catherine N., "Export Performance: Do Mancgerial Perceptions Make A Difference?", International Marketing Review, Summer 1988.

Bilkey Waren J., "An Attempted Integration of the Literature on the Export Behavior of Firms", Journal of International Business Studies, Spring/Summer 1978, Vol:9, No:1.

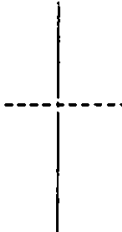

-, George Tesar, "The Export Bchavior of Smaller-Sized Wisconsin Manufacturing Firms", Journal of International Business Studies, 1977, Spring/Summer, Vol:8, No:1.

Bonarccorsi Andrea, "On the Relationship Between Firm Size and Export Intensity", Journal of International Business Studies, 1992, First Quater.

Bradley M. Frank, "Attitudes to Export Marketing Growth Among Small Scale Entcrprises: A Discriminant, Analysis", Marketing:Future Imperfect, 
Proceeding of Marketing Education Group Annual Conference, Ed: Philip R. Flood,Campbell L. Grant, Aidan OíDriscoll,Vol:1,Dublin,July 1981.

Brady Donald L., William O. Bcarden, "The Effect of Managerial Attitudes on Alternative Exporting Models", Journal of International Business, Winter 1979.

Canon T., McAuley A., McKay J., "Internationalization and the Role of Marketing", Scottish Enterprise Foundation, Occasional Paper Series, No:25/88, August 1988.

Çavuşgil S. Tamer, "On the Internationalization Process of Firms", European Researh, November, 1980.

, "Organizational Characteristics Associated with Export Activity", Journal of Managemet Studies, 1984, Vol:21, No:1.

, Jacob Naor, "Firm And Management Characteristics as Discriminators of Export Marketing Activity", Journal of Business Research ,1987, Vol:15.

, John R. Nevin, "Internal Determinats of Export Marketing Behaviour: An Empirical Investigation", Journal of Marketing Research, 1981, Vol:18, No:1.

, Yczdi M. Godiwalla, "Decision-Making for Interntional Marketing: A Comparetive Review", Management Decision, 1982, Vol:20, No:4.

Cooper Robert G., Kleinschmidt J. Elko, "The Impact of Export Strategy on Export Sales Performance", Journal of International Business Studies, Spring 1985.

Devrez Güney, Piyasa Araştırmalarında Bilgi Toplama Metotları, Sevinç Matbaası, Ankara, 1971.

Diamantopoulos Adamantios, B.B. Schlegelmilch, C. Allpress, "Export Marketing Research in Practice: A Comparison of User and Non-Users", Journal of Marketing Management, 1990, Vol:6, No:3.

Karen Inglish, "Identifying Differences Between High and Low Involvement Exporters", International Marketing Review, Summer 1988.

Dichll Erwin, Hans-George Koeglmayr, Stefan Mueller, "International Orientation as a Precondition for Export Success", Journal of International Business Studies, 1990, Vol:19, No:2.

, M. Leibold, H.G. Kölmayr, S. Müller, "The Export Decision of Small and Medium Sized Firms: A Revicw", Management International Review, 1984, Vol:24, No:2. 
Edmuns Stahrl E., Sarkis J. Khoury, "Exports:- A Necessary Ingredient in the Growth of Small Business Firms", Journal of Small Business Management, October 1986, Vol:24, No:4.

Eshghi Abdolreza, "Attitude- Behaviour Inconsistency in Exporting", International Marketing Review, 1992, Vol:9, No:3.

Holzmüller Harmut H., Helmut Kasper, "On a Theory of Export Performance: Personel and Organizational Determinants of Export Trade Activiyies Observed in Small and Medium-Sized Firms", Management International Review, 1991, Vol:31, Special Issue.

Jatusripitak Somkid, The Export Behavior of Manufacturing Firms, UMI Research Press, Michigan. 1986.

Johansan Jan, Jan-Erik Vahlne, "The Internationalization Process of The Firm-A Model of Knowledge Development and Increasing .Foreign Market Commitments", Journal of International Business Studies, 1977, Vol:8, No:1.

, Finn Wiedersheim-Paul, "The Internationalizaton of The Firm-Four Swedish Cases", Journal of Management Studies, October 1975.

Johnston Wesley J., Michael R. Czinkota, "Export Attitudes of Industrial Manufacturing", Industrial Marketing Management, 1985, Vol:14.

Kirpalani V.H., N.B. Macintosh, "International Marketing Efectiveness of Tecnologyoricnted Small firms"., Journal of International Business Studies, Winter 1980.

Koçàk F.Akın, "Davranışsal Açıdan Türkiye'de Küçük ve Orta Ölçckli Işletmelerin thracat Pazarlanıası Kaırar Alma Süreci", Yayınlanmamıs Doktora Tezi, Ankara Üniveısilesi Sosyal Bilimler Enstitüsü, Ankara, 1997.

Madsen Tage Koed, "Successful Export Marketing Management: Some Empirical Evidence", International Marketing Review, 1989, Vol:6, No:4.

McGuinness Norman W., Blair Litule, "The Influence of Product Characteristics on the Export Performance of New Industrial Products", Journal of Marketing, Spring 1981, Vol:45.

Miesenbock Kurt J., "Small Business and Exporting: A Literetute Review", International Small Business Journal, Jan.-Mar. 1988, Vol:6, No:2.

Morelend Harold D., "A Summary of the Internationalization Process of Smaller Enterprises and the Related Literature", Department of Business Studies, University of Edinburg, Working Paper Series, No:90/8, Edinburg, 1990. 
Müftüoğlu M.Tamer, Türkiye'de Küçük ve Orta Ölçekli Iş̧letmelerSorunlar* Öneriler, Sevinç Yayınevi, Ankara, 1990.

O'Rouke A. Desmond, "Differences in Exporting Practices, Attitudes and Problems by Size of Firm", American Journal of Small Business, 1985, Vol:9, No:3.

Olson Hans Christer, Finn Wiedersheim-Paul, "Factors Affecting The Pre-Export Behaviour of Non-Exporting Firms", European Resaerch In International Business, Ed:Micheal Gretman, James Leontiades, NortHolland Publishing Company, Amesterdam, 1978.

Reid Stan D., "Managerial and Firm Influences on Export Behavior", 1983, Journal of The Academy of Marketing Sciences, Summer 1983, Vol:11, No:3.

--------, "The Desicion Maker and Export Entry and Expansion", Journal of Intenational Business Studies, Fall 1981, Vol:12, No:2.

Roux Elyette, "Manager's" Attitudes Towards Risk Among Determinants of Export Entry of Small and Medium- Sized Firms", Managing Export Entry and Expansion, Ed:Philip J. Rosson, Stanley Reid, Praeger Publishers, New York, 1987.

Roy Delwin A., Claude L. Simpson, "Export Attitudes of Business Executives in the Smaller Manufacturing Firm", Journal of Small Business Management, April 1981.

Roy Delwin, Claude L. Simpson, "Export Attitudes of Business Executives in The Smaller Manufacturing Firm", Journal of Small Business Management, April 1981, Vol:19, No:2.

Seringhaus Rolf, "The Role of Information Assistance in Small Firmís Export Involvement", International Small Business Journal, Winter 1986/1987, Vol:5, No:2.

Simmons Keneth, Helen Smith, "The First Export Order: A Marketing Innovation", British Journal of Marketing, Summer 1968.

Sood James H., Patrick Adams, "Model of Management Learning Styles as a Predictor of Export Behavior and Performance", Journal of Business Research, 1984, Vol:12.

Suzman Cedric, Lawrence Wortzel, "Technology Profilc and Export Marketing Strategics", Journal of Business Research, 1984, Vol:12, No:2.

Thomas Michael J., Luis Araujo, "Theories of Export Behaviour: A Critical Analysis", European Journal of Marketing, Summer 1985. 
Üner M. Mithat, "Ankara Sanayi Odasına Kayıth Işletmeleri thracattan Alıkoyan Nedenler", Siyasal Bilgiler Fakültesi Dergisi, Prof. Dr. Yılmaz Günal'a Armağan, Cilt: 49, Sayı: 3-4, 1994.

VakıfBank, KOBI'lerde thracat Pazarlaması ve thracaun Finansmanı, VakıfBank Araştırma Dizisi 5, 1994, Ankara.

Wiedersheim-Paul Finn, Hans C. Olson, Lawrence S.Welch, "Pre-Export Activity: The First Step in Internatianalization", Journal of International Business Studies, 1978, Vol:9, No:1, spring/ Summer.

Woo-Young Lee, John J. Brasch, "The Adoption of Export As An Innovative Strategy", Journal of Intenational Business Studies, 1978, Vol:9, No:1. 